\title{
Depletion of $14-3-3 \gamma$ reduces the surface expression of Transient Receptor Potential Melastatin 4b (TRPM4b) Channels and attenuates TRPM4b-mediated glutamate-induced neuronal cell death
}

\author{
Chang-Hoon Cho ${ }^{1,2+}$, Eunju Kim ${ }^{1,3+}$, Young-Sun Lee ${ }^{3}$, Oleg Yarishkin ${ }^{1}$, Jae Cheal Yoo ${ }^{3}$, Jae-Yong Park,3, \\ Seong-Geun Hong ${ }^{3 *}$ and Eun Mi Hwang ${ }^{1,4^{*}}$
}

\begin{abstract}
Background: TRPM4 channels are $\mathrm{Ca}^{2+}$-activated nonselective cation channels which are deeply involved in physiological and pathological conditions. However, their trafficking mechanism and binding partners are still elusive.

Results: We have found the 14-3-3y as a binding partner for TRPM4b using its N-terminal fragment from the yeast-two hybrid screening. Ser88 at the N-terminus of TRPM4b is critical for 14-3-3y binding by showing GST pull-down and co-immunoprecipitation. Heterologous overexpression of 14-3-3y in HEK293T cells increased TRPM4b expression on the plasma membrane which was measured by whole-cell recordings and cell surface biotinylation experiment. Surface expression of TRPM4b was greatly reduced by short hairpin RNA (shRNA) against 14-3-3y. Next, endogenous TRPM4b-mediated currents were electrophysiologically characterized by application of glutamate and 9-phenanthrol, a TRPM4b specific antagonist in HT-22 cells which originated from mouse hippocampal neurons. Glutamate-induced TRPM $4 b$ currents were significantly attenuated by shRNAs against 14-3-3y or TRPM4b in these cells. Finally, glutamate-induced cell death was greatly prevented by treatment of 9-phenanthrol or 14-3-3y shRNA.
\end{abstract}

Conclusion: These results showed that the cell surface expression of TRPM4 channels is mediated by 14-3-3 $\gamma$ binding, and the specific inhibition of this trafficking process can be a potential therapeutic target for glutamate-induced neuronal cell death.

Keywords: TRPM4b, 14-3-3, Non-selective cation channels, 9-phenanthrol, HT-22, Protein-protein interaction, Surface expression, Hippocampal neurons, Calcium activated cation channels, MTT assay

\section{Background}

The calcium ion $\left(\mathrm{Ca}^{2+}\right)$ is the most abundant signaling molecule in regulating physiological and cellular functions [1]. Therefore, it is natural that $\mathrm{Ca}^{2+}$-permeable membrane proteins have been vigorously studied to understand their

\footnotetext{
*Correspondence: hong149@gnu.ac.kr; emhwang@kistre.kr

${ }^{\dagger}$ Equal contributors

${ }^{3}$ Department of Physiology, Institute of Health Science and Medical Research Center for Neural Dysfunction, Gyeongsang National University School of Medicine, Jinju 660-51, Republic of Korea

${ }^{1} \mathrm{WCI}$ Center for functional connectomics, Korea Institute of Science and Technology (KIST), Seoul 136-791, Republic of Korea

Full list of author information is available at the end of the article
}

dynamic actions: voltage-gated $\mathrm{Ca}^{2+}$ channels, $\mathrm{Ca}^{2+}$-permeable TRP (Transient Receptor Potential) channels, ligand-gated $\mathrm{Ca}^{2+}$-permeable receptors (e.g., ionotrophic glutamate receptors, purinergic receptors and nicotinic acetylcholine receptors), and intracellular receptors such as ryanodine and $\mathrm{IP}_{3}$ receptors [2-5]. In addition, $\mathrm{Ca}^{2+}$-activated $\mathrm{K}^{+}$channels (BK, IK, and SK), and $\mathrm{Ca}^{2+}$-activated $\mathrm{Cl}^{-}$channels (Bestrophins and Anoctamins) are getting more attentions recently [6,7].

Although $\mathrm{Ca}^{2+}$-activated $\mathrm{Na}^{+}$channels have yet to be found, $\mathrm{Ca}^{2+}$-permeable non-selective cation channels are numerous (e.g., NMDA receptors and TRPC channels).

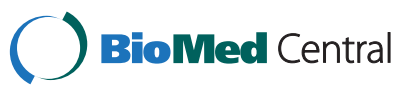

(c) 2014 Cho et al.; licensee BioMed Central Ltd. This is an Open Access article distributed under the terms of the Creative Commons Attribution License (http://creativecommons.org/licenses/by/4.0), which permits unrestricted use, distribution, and reproduction in any medium, provided the original work is properly credited. The Creative Commons Public Domain Dedication waiver (http://creativecommons.org/publicdomain/zero/1.0/) applies to the data made available in this article, unless otherwise stated. 
In contrast, $\mathrm{Ca}^{2+}$-impermeable non-selective cation channels are only a few: AMPA receptors (except for AMPA receptors with calcium permeable unedited GluR2 subunit or without GluR2 subunit) and TRPM4 and TRPM5 [8-11]. TRPM4 and TRPM5 have been identified as $\mathrm{Ca}^{2+}$-activated, $\mathrm{Ca}^{2+}$-impermeable monovalent cation channels whose activities have been first reported more than three decades ago [12-16]. They conduct $\mathrm{Na}^{+}$and $\mathrm{K}^{+}$ according to the concentration gradient of individual ion when activated by membrane depolarization and an increase in intracellular calcium $\left(\left[\mathrm{Ca}^{2+}\right]_{\mathrm{i}}\right)$ [14-17]. They belong to a subgroup (melastatin-related TRPM) of TRP channels with six transmembrane domains which forms a functional channel as a tetramer [18,19].

TRPM4 channels are expressed in various tissues including brain [20-22]. Mutations in TRPM4 gene and their consequential dysfunction have been linked to cardiac diseases [23-25]. The increased level of TRPM4 channels has been reported in vascular endothelium following hypoxia/ischemia, in the endothelial cells of capillary vessels following spinal cord injury [26,27]. In the brain, expression and/or channel activities of TRPM4 have been detected in hippocampus, cerebellar Purkinje cells, preBötzinger complex in the brainstem, magnocellular cells in supraoptic and paraventricular nuclei, and substantia nigra pars compacta [28-32]. Recently, TRPM4 has been shown to be important in neuronal cell death of experimental autoimmune encephalomyelitis and human multiple sclerosis tissues [31]. Therefore, understanding trafficking mechanism of TRPM4 channels to the plasma membrane may open the therapeutic window to intervene the underlying TRPM4-related diseases.

\section{Results and discussions}

Identification of $14-3-3 \gamma$ as a binding partner of TRPM4b We previously reported that TRPM4 isoforms have differential expression on the plasma membrane: the full-length TRPM4b channels are highly localized on the plasma membrane, in contrast, TRPM4a lacking the N-terminal 174 amino acids is rarely present on the plasma membrane [22]. To identify the potential binding partner(s) for the surface expression of TRPM4b based on this observation, we made a bait construct of the intracellular N-terminal fragment (N174) of human TRPM4b for the conventional yeast two-hybrid $(\mathrm{Y} 2 \mathrm{H})$ screening (Figure 1A). Among the positive clones, we found human 14-3-3 $\gamma$ as a binding partner for TRPM4b (Figure 1B). They formed a positive yeast colony in $\mathrm{Y} 2 \mathrm{H}$ under the non-permissive condition, while the empty vector did not. To examine the interaction between TRPM4b and $14-3-3 \gamma$ in the mammalian system, we constructed expres-

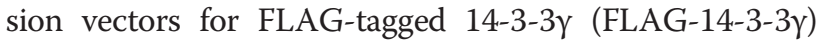
and GFP-tagged TRPM4b (GFP-TRPM4b) or GFP-tagged
N174, and co-expressed them in HEK293T cells. We then performed co-immunoprecipitation (Co-IP) on cell lysates with an anti-FLAG antibody and blotted with an anti-GFP antibody. The results showed that GFP-TRPM4b was strongly associated with FLAG-14-3-3y (Figure 1C). The inverse experiment with anti-GFP antibody for Co-IP and anti-FLAG antibody for blotting showed the consistent result (see Additional file 1: Figure S1A). We then examined the interaction between TRPM4b and 14-3-3 $\gamma$ at the single-cell level to verify this interaction. We used the bimolecular fluorescence complementation (BiFC) technique, which allows visualization of two independent proteins in close spatial proximity [33]. We constructed TRPM4b and 14-3-3y, whose $\mathrm{N}$ - and C- termini were fused to one complementary half of split Venus fluorescent protein, either $\mathrm{N}$-terminal half (VN) or C-terminal half (VC), and then both were transfected into HEK293T cells (Figure 1D). Strong fluorescence was detected when the split Venus halves were on complementary positions (VC-TRPM4b and VN-14-3-3y). The BiFC fluorescent signal was detected at the plasma membrane of the cells, shown in yellow (Figure 1D). In contrast, weak BiFC signal was detected from the cells transfected with VC-TRPM4a and VN-14-3-3y (see Additional file 1: Figure S1B top panel). As a negative control, when TRPM4b or 14-3-3y was expressed with only one half of split Venus, no fluorescence was detected. These results suggest that an association between TRPM4b and 14-3-3y occurs in live mammalian cells. We further examined that other 14-3-3 isoforms could bind to N174 by using several FLAG-tagged 14-3-3 isoforms for Co-IP with anti-FLAG and anti-GFP antibodies. The result showed that binding of $14-3-3 \gamma$ to TRPM4b is isoform-specific (Figure 1E). BiFC experiment using TRPM4b and 14-3-3 $\sigma$ produced the weak signal (see Additional file 1: Figure S1B low panel).

\section{Ser88 at the N-terminus of TRPM4b is critical for 14-3-3 $\gamma$ binding}

Next, we investigated which amino acid residues of TRPM4b are critical for 14-3-3 $\gamma$ binding. Through the Motif Scan database [http://scansite.mit.edu/motifscan_seq. phtml] three putative phosphorylation sites for $14-3-3 \gamma$ binding were predicted on the N174 (Figure 2A). To identify the critical residue(s) for $14-3-3 \gamma$ binding we replaced Thr19, Thr42 and Ser88 sites of GFP-TRPM4bN174 to Ala individually (T19A, T42A, and S88A). From GST (Glutathione-S-transferase)-pull down with these mutants, we found that only S88A mutant proteins failed to interact with 14-3-3 $\gamma$ (Figure 2B). Co-IP experiment also revealed a drastic reduction in binding

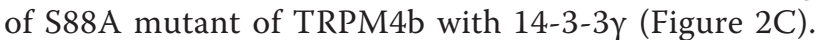
In addition, a multiple sequence alignment shows that Serine 88 of TRPM4b is highly conserved in four vertebrate species (Figure 2D). 


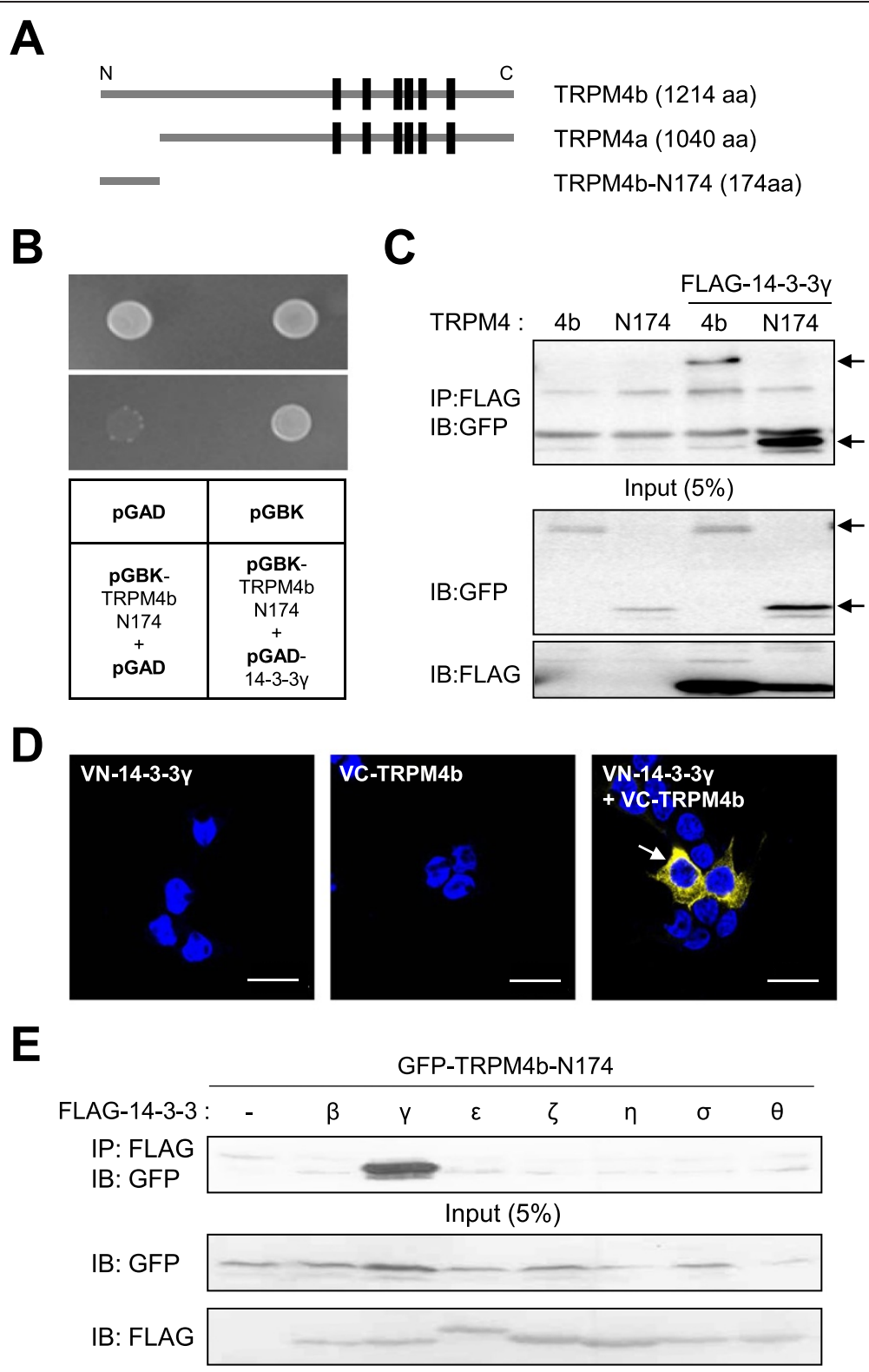

Figure 1 TRPM4b associates with 14-3-3y in heterologous systems. (A) Diagram of the full length TRPM4b, a splice variant TRPM4a, and a short TRPM4b N-terminal fragment (TRPM4b-N174) used in this study. (B) Identification of 14-3-3 $\gamma$ as a direct binding partner of TRPM4b in the yeast two-hybrid system. (C) Co-IP experiment. GFP-TRPM4b (4b) or GFP-TRPM4b-N174 (N174) was transfected with or without FLAG-14-3-3y in HEK293T cells and cell lysates were then immunoprecipitated using anti-FLAG antibody. Immunoprecipitates were examined by Western blotting using anti-GFP antibody (upper panel). Input represented 5\% of cell lysates used in the Co-IP experiment (lower panel). (D) BiFC experiment with VN-14-3-3y and VC-TRPM4b, where N- and C-terminal halves of Venus fluorescent protein were fused to 14-3-3 $\gamma$ and TRPM4b, respectively. Intense fluorescent signals were detected by the yellow color (arrow). Scale bar, $10 \mu \mathrm{m}$. (E) 14-3-3ץ specifically binds to GFP-TRPM4b-N174 among seven 14-3-3 isoforms.

Surface expression of TRPM4b is mediated by $14-3-3 \gamma$ Based on our result that TRPM4b binds to 14-3-3y and on the information that 14-3-3 proteins are deeply involved in trafficking of membrane proteins [34], we hypothesized that 14-3-3 $\gamma$ increases the surface expression of TRPM4b channels. In cell surface biotinylation experiment, GFP-TRPM4b was markedly increased on the plasma membrane in the presence of HA-14-3-3y (Hemagglutinin-tagged 14-3-3y); however no significant changes in total cell lysate levels of TRPM4b were detected (Figure $3 \mathrm{~A}$ and $\mathrm{B}$ ).

Next, we measured TRPM4b-mediated whole-cell currents elicited by $1 \mu \mathrm{M}$ ionomycin from the HEK293T cells overexpressing GFP-TRPM4b with or without 


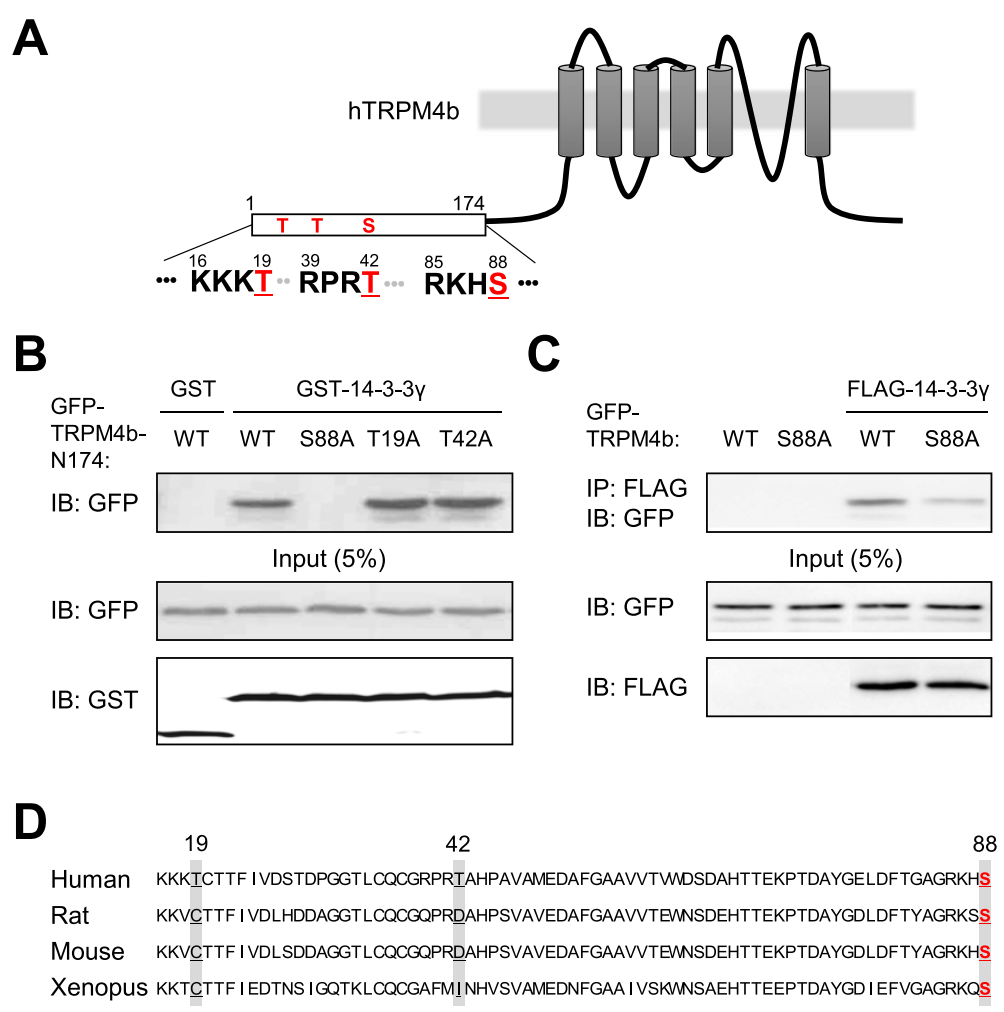

Figure 2 Interaction of TRPM4b with 14-3-3y may require a conserved serine phosphorylation residue. (A) Schematic diagram depicting the membrane topology of hTRPM4b channels. Conserved phosphorylation residues (T19, T42, and S88) predicted for 14-3-3 binding were marked in the intracellular N-terminal domain (N174). These residues are highlighted in red. (B) GST-pulldown was performed on lysates of HEK293T cells co-expressing GST-14-3-3Y and GFP-TRPM4b-N174 or each mutant (S88A, T19A, and T42A). Cell lysates were immunoprecipitated using anti-GST antibody and immunoprecipitates were examined by Western blotting using anti-GFP or anti-GST antibody. Input represented 5\% of cell lysates used. (C) Co-IP experiment was performed on lysates of HEK293T cells co-expressing FLAG-TRPM4b (WT) and its mutant (S88A). Cell lysates were immunoprecipitated using anti-FLAG antibody and immunoprecipitates were examined by Western blotting using anti-GFP or anti-FLAG antibody. Input represented 5\% of cell lysates. (D) Sequence comparison of the region of conserved phosphorylation sites for 14-3-3 binding in hTRPM4b among human, rat, mouse and Xenopus. Only Ser88 was conserved over the species.

mCherry-14-3-3y using the voltage-ramp from -100 to $+100 \mathrm{mV}$ [15]. Currents were measured at $5 \mathrm{~min}$ after ionomycin application and ionomycin-activated currents were calculated by subtracting the initial currents from them (Figure $3 \mathrm{C}$ and $\mathrm{D}$ ). The current density from cells overexpressing TRPM4b and 14-3-3 $\gamma$ were significantly larger than the ones from cells overexpressing TRPM4b alone. In addition, the currents from cells overexpressing TRPM4b-S88A mutants were negligible and similar to the ones from non-transfected cells. Alternatively, using the pipette solution including $30 \mu \mathrm{M}\left[\mathrm{Ca}^{2+}\right]_{\mathrm{i}}$ the current density from the cells overexpressing both TRPM4b and 14-3-3y were more than two-folds larger than those from the cells overexpressing TRPM4b alone (see Additional file 2: Figures S2A and B).

\section{Deficiency of 14-3-3y reduces the surface expression of TRPM4b in HEK293T cells}

To examine the effect of depletion of endogenous 14-3-3y on the cell surface expression of overexpressed TRPM4b

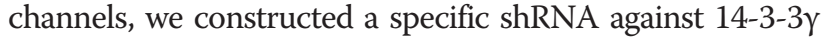
and verified the efficiency of $14-3-3 \gamma$ shRNA. There was

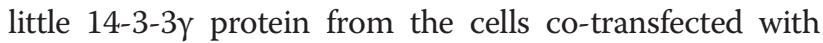

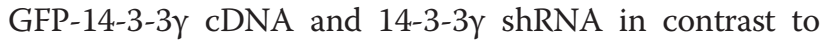
the cells co-transfected with scrambled (Sc) shRNA by Western blot (Figure 4A). Endogenous 14-3-3y mRNAs in HEK293T cells were also efficiently knock-downed in 14-3-3y shRNA-transfected cells as shown in RT-PCR (Figure 4B). Next, we examined whether the surface expression of TRPM4b can be reduced by 14-3-3y shRNA using cell surface biotinylation experiment. As expected, the surface expression of TRPM4b was markedly reduced (Figure $4 \mathrm{C}$ and D). We examined the co-localization with GFP-TRPM4b and DsRed-Mem, a plasma membrane marker to determine the effect of 14-3-3y shRNA on the subcellular localization of TRPM4b (Figure 4E). GFPTRPM4b channels were highly localized at the plasma membrane of HEK293T cells in the presence of Sc shRNA, as evidenced by a yellow color in the enlarged image (arrow in the top right panel), while they were less 
A

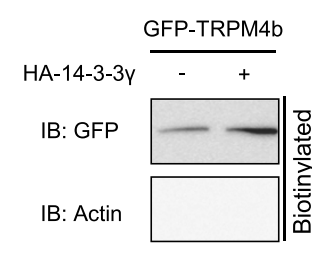

IB: GFP IB: HA IB: Actin

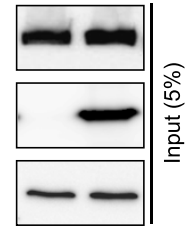

B

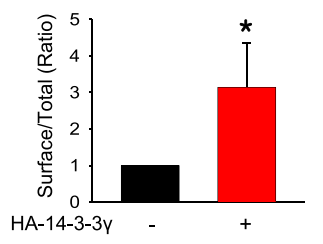

C

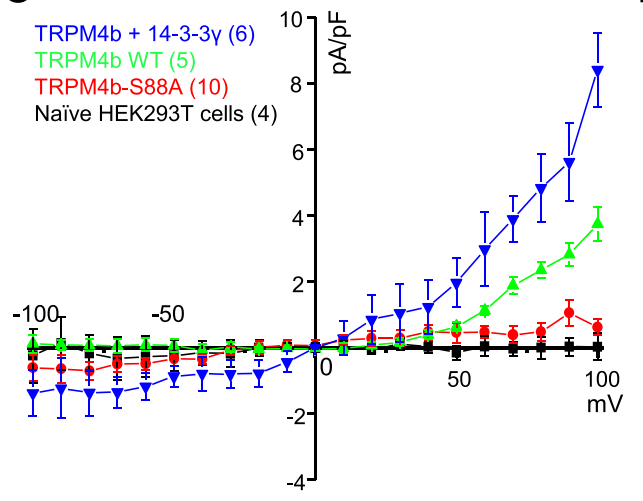

D

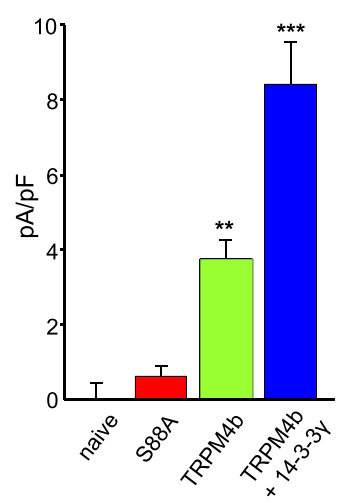

Figure 3 The current density of TRPM4b channel is increased by 14-3-3y co-expression. (A) Surface biotinylation experiment was

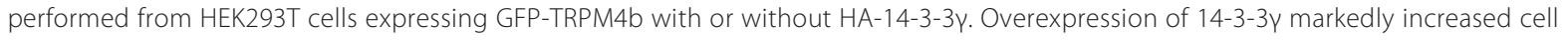
surface expression of TRPM4b. (B) Summary bar graph of TRPM4b level with or without 14-3-3y co-expression was shown as a ratio of surface to total TRPM4b $(n=4)$. (C) The current densities were obtained from whole-cell currents of non-transfected HEK293T cells (black; $n=4)$, cells transfected with GFP-TRPM4b (green; $n=5$ ), cells transfected with S88A TRPM4b mutant (red; $n=10$ ) and cells co-transfected with GFP-TRPM4b and 14-3-3y (blue; $\mathrm{n}=6$ ). Currents were activated by $1 \mu \mathrm{M}$ ionomycin and the voltage-ramp $(-100 \mathrm{mV}$ to $+100 \mathrm{mV})$. The current densities were calculated by subtracting the amplitude of initial currents from $1 \mu \mathrm{M}$ ionomycin-activated currents and divided by cell capacitance. (D) Summary bar graph of TRPM4b currents with or without 14-3-3y co-expression was plotted at $+100 \mathrm{mV}\left({ }^{* *} p<0.01\right.$ and $\left.{ }^{* * *} p<0.001\right)$. All values are mean \pm SEM.

localized at the plasma membrane in the presence of 14-3-3 $\gamma$ shRNA (arrowhead in the middle right panel). As shown in Figures 2B and C, TRPM4b-S88A mutant, which $14-3-3 \gamma$ interaction was greatly reduced, was also less localized on the plasma membrane (arrowhead in the bottom right panel). Reduced membrane localizations of TRPM4b with 14-3-3y shRNA and TRPM4b-S88A were shown in a bar graph of Pearson's correlation coefficient $(\mathrm{P}<0.001$; Figure 4F).

\section{Glutamate-induced activation of endogenous TRPM4b in neuronal cells from hippocampus}

Recently, the deficiency of TRPM4 has been shown to be neuroprotective from glutamate-induced cell death in experimental autoimmune encephalomyelitis, a mouse model of human multiple sclerosis [31]. This report leads us to hypothesize that interference of TRPM4b function via blocking its trafficking to the plasma membrane with $14-3-3 \gamma$ shRNA may have a protective effect from glutamate neurotoxicity. To test this hypothesis we first characterized TRPM4b-mediated currents in HT-22 cells, originated from mouse hippocampal neurons, which have been frequently used as an in vitro model for glutamate-induced neurotoxicity [35].

We measured whole-cell currents which were elicited by voltage-ramp pulses (400 ms) assessing from -100 $\mathrm{mV}$ to $+100 \mathrm{mV}$ from the holding potential of $0 \mathrm{mV}$. After obtaining steady-state responses (10-20 sweeps), glutamate $(1 \mathrm{mM})$ was applied to the bath solution. Glutamate-induced currents were elicited within 3-4 minutes upon glutamate application and they reached near-maximal values within 10 minutes as originally shown [16] (see Additional file 3: Figure S3A). The glutamate-induced component had strong outward rectification and the reversal potential was close to $0 \mathrm{mV}$ (Figure 5A and B). The current amplitude of glutamateinduced currents depicted at $100 \mathrm{mV}$ was $9.87 \pm 2.0$ (mean \pm SEM, $n=6$ ) folds larger than the ones before glutamate application (Figure 5A and B). To verify whether the glutamate-induced currents were TRPM4mediated, we used 9-phenanthrol, a selective TRPM4specific antagonist [36]. 9-phenanthrol was applied to the bath solution $10 \mathrm{~min}$ after glutamate application when near-maximal glutamate-induced currents were obtained. 


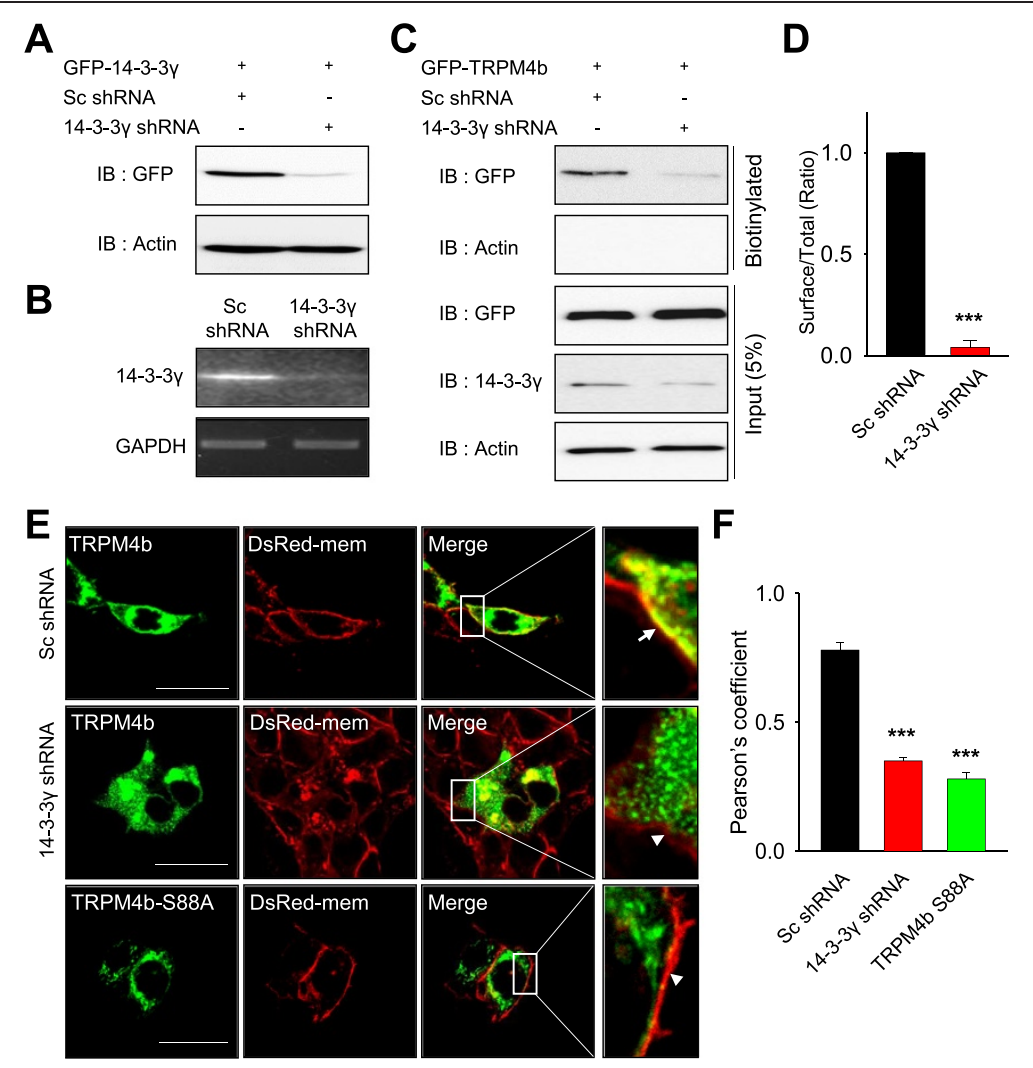

Figure 4 The shRNA-mediated knockdown of 14-3-3y reduced the surface expression of TRPM4b channels. (A) 14-3-3y shRNA eliminated

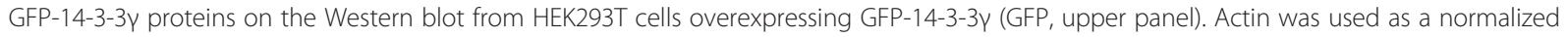
control. (B) 14-3-3y shRNA reduced the level of 14-3-3y mRNA in HEK293T cells as examined by RT-PCR. GAPDH was used as an internal control. (C) Surface biotinylation experiment was performed from HEK293T cells expressing GFP-TRPM4b with Scrambled (Sc) or 14-3-3y shRNA. The knockdown of 14-3-3y markedly decreased cell surface expression of TRPM4b. (D) Summary bar graph of TRPM4b level with Sc or 14-3-3y shRNAs co-expression was shown as a ratio of surface to total TRPM4b $(n=4)$. (E) GFP-TRPM4b was co-transfected with Sc shRNA (upper panel) or 14-3-3y shRNA (middle panel) in HEK293T cells with DsRed-Mem, a plasma membrane marker. Intracellular localization of GFP-TRPM4b was visualized by confocal microscopy (left panels). GFP-TRPM4b-S88A was also shown in (bottom panel). Merged images were shown (right panel) and plasma membranes were indicated by an arrow and arrowheads in enlarged image. Scale bars, $10 \mu \mathrm{m}$. (F) The Pearson's correlation coefficient for TRPM4b with 14-3-3y shRNA or TRPM4b-S88A was significantly less than values obtained with Sc shRNA in HEK293T cells $(P<0.001)$. The Pearson's correlation coefficient denoting covariance of fluorescence signals was calculated using Nikon A1 software.

Within 2 minutes of application of 9-phenanthrol (100 $\mu \mathrm{M})$, the glutamate-induced currents were inhibited by $82.8 \pm 2.9 \%$, which is similar to the reported percentage of TRPM4 inhibition by 9-phenanthrol [37]. In addition, in the presence of 9-phenanthrol, glutamate failed to activate TRPM4b-mediated currents in HT-22 cells (see Additional file 3: Figure S3B).

We also examined the endogenous expression of TRPM4b in HT-22 cells by quantitative RT-PCR. As shown in Additional file 3: Figure S3C, TRPM4b expression in HT-22 cells was comparable to its expression in cultured hippocampal neurons. To rule out the possibility of glutamate-induced current activation through other than TRPM4b channels, we designed specific shRNAs against TRPM4b and found two functional shRNA constructs (see Additional file 3: Figure S3D). Glutamateelicited currents was indeed failed to be activated in
HT-22 cells transfected with a specific TRPM4b shRNA (Figure 5C and D). In summary, this data clearly showed that HT-22 cells have functional TRPM4b channels which can be elicited by glutamate.

Now, to examine the efficient interference of TRPM4b trafficking with 14-3-3y shRNA, we measured glutamateinduced TRPM4b currents in HT-22 cells transfected with either 14-3-3y shRNA or Sc shRNA. In contrast to the current amplitude of glutamate-induced TRPM4b channels in the cells transfected with Sc shRNA, the one in the cells transfected with 14-3-3y shRNA was drastically reduced even 20 min after glutamate application $(\mathrm{P}<0.001$; Figure $5 \mathrm{C}$ and $\mathrm{D}$ ).

Lastly, we asked whether inhibition of activity and trafficking of TRPM4b may prevent the neuronal cells from glutamate-induced cell death. First, we tested the effect of 9-phenanthrol on the glutamate-induced cell death 


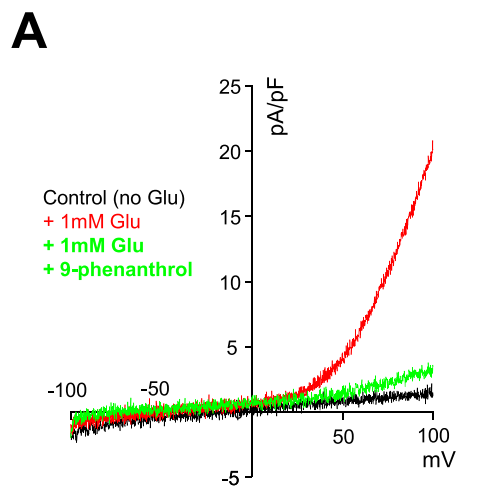

C

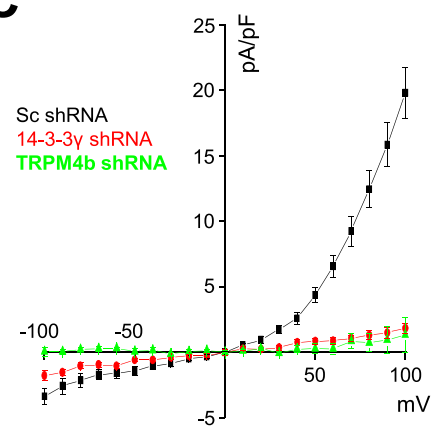

$\mathbf{E}$

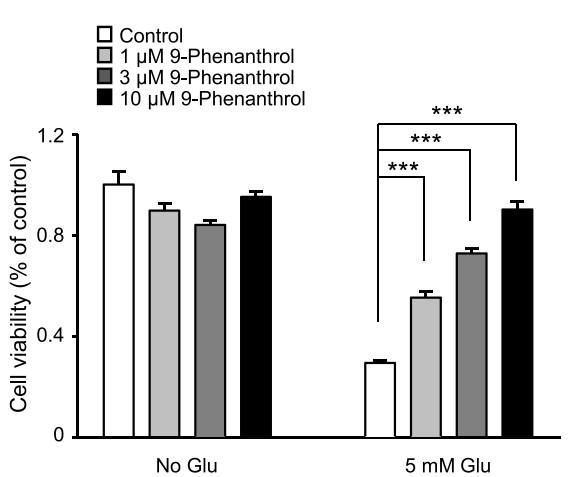

B
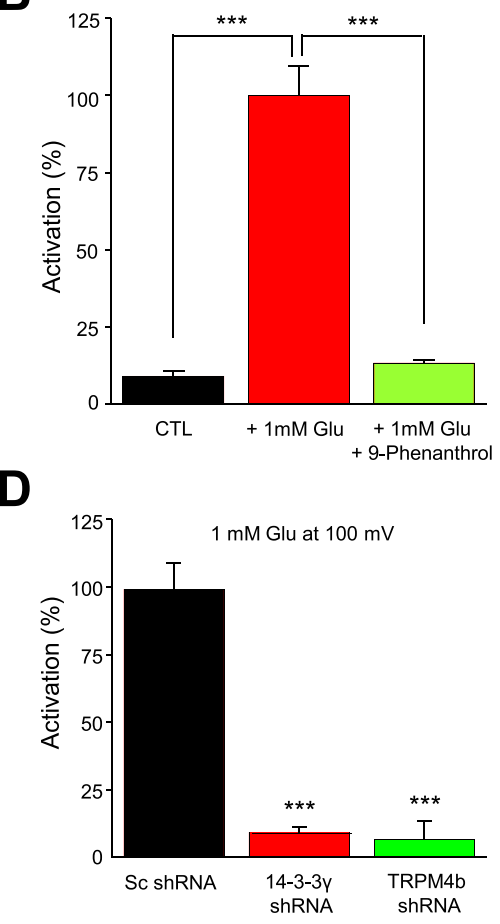

$\mathbf{F}$

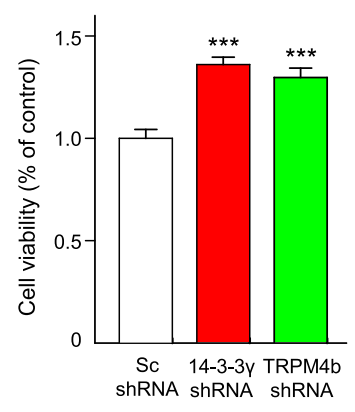

Figure 5 Inhibition of TRPM4b channel activity increases cell survival from glutamate-mediated excitotoxicity in HT-22 cells. (A) A representative whole-cell recording showed that the endogenous TRPM4b activation was induced by glutamate (1 mM) application and TRPM4b-activated currents were inhibited by 9-phenanthrol in HT-22 cells. (B) The summary bar graph showed the mean values of activation of TRPM4b by glutamate $(1 \mathrm{mM})$ and its inhibition by 9-phenanthrol $(100 \mu \mathrm{M})$ in HT-22 cells $(\mathrm{P}<0.001 ; n=7)$. (C) Glutamate-induced TRPM4b currents in HT-22 cells was impaired with 14-3-3y or TRPM4b shRNAs but not with Sc shRNA $(n=6)$. (D) The bar graph showed that the current amplitudes of TRPM4b channels transfected either with $14-3-3 \gamma$, TRPM4b or Sc shRNAs $(P<0.001 ; n=6)$. (E) The bar graph showed the results of MTT assay which glutamate-induced cell death was prevented by 9-phenanthrol dose-dependently $(P<0.001 ; n=24)$. (F) The bar graph showed that shRNA against 14-3-3y or TRPM4b shRNAs significantly reduced glutamate-induced cell death in HT-22 cells $(P<0.001 ; n=24)$.

using the MTT assay since 9-phenanthrol blocked TRPM4b channels effectively in whole-cell recordings. The great number of HT-22 cells was killed after glutamate $(5 \mathrm{mM})$ treatment $(69.57 \pm 0.92 \%(\mathrm{n}=24)$; Figure $5 \mathrm{E})$. In comparison, the cell death was dramatically reduced by 9 -phenanthrol in a dose-dependent manner and no significant difference in control cells (without glutamate treatment) was detected (Figure 5E). We also examined the effect of $14-3-3 \gamma$ shRNA on the cell viability in glutamate-treated HT-22 cells. Compared to the HT-22 cells transfected with Sc shRNA, knockdowns of 14-3-3y and TRPM4b increased the cell survival $(136.1 \pm 3.6 \%$ $(n=24)$ and $129.8 \pm 4.6 \%(n=6)$, respectively; Figure $5 F)$.

\section{4-3-3 $\gamma$-mediated TRPM4b trafficking mechanism provides a potential therapeutic target}

14-3-3 proteins are one of most important 'hub' proteins involved in diverse cellular processes in all eukaryotes 
[34]. Their isoforms are broadly expressed in nervous systems and involved in many physiological conditions (such as hippocampal long-term potentiation) as well as neurodegenerative and neuropsychiatric diseases [38-41]. 14-3-3 proteins bind to a lot of membrane proteins including ion channels such as TASK-1 and TASK-3, TRESK, $\mathrm{K}_{\mathrm{ATP}}$ channels, hERG/I $\mathrm{I}_{\mathrm{Kr}}$ channels, $\mathrm{Na}_{\mathrm{V}} 1.5$, $\mathrm{Ca}_{\mathrm{V}} 2.2, \mathrm{GABA}_{\mathrm{B}}$ receptors, neuronal nicotinic $\alpha 4 \beta 2$ receptors, NMDA receptor subunit NR2C, kainate receptor subunit GluK2 and GluK5 [42-53]. Among isoforms, 14$3-3 \gamma$ has been shown to interact with a large-conductance $\mathrm{Ca}^{2+}$-activated $\mathrm{K}^{+}(\mathrm{BK})$ channels and increases their surface expression as shown in this study [54]. In general, 14-3-3 proteins bind to (mostly) phosphorylated target proteins at the specific site(s) and function as a dimer [34]. A previous study showed that PKC $\delta$ activation increased the surface expression of TRPM4 channels in vascular smooth muscle cells [55]; however, two putative PKC phosphorylation sites are localized at the C-terminus of TRPM4 channels [56]. Since 14-3-3y binds to the Nterminus of TRPM4b in this study, kinase(s) other than PKC may be involved in 14-3-3 $\gamma$-mediated trafficking of TRPM4b channels.

A recent report showed that the glutamate-induced neuronal cell death was absent in TRPM4 null mice [31] and our results also clearly showed that inhibition of TRPM4b function either by a specific inhibitor or interfering trafficking of TRPM4b channels to the plasma membrane via 14-3-3 $\gamma$ shRNA blocked glutamate-induced cell death (Figure 5). Therefore, TRPM4b channels can be new therapeutic targets. R18 and difopein (dimeric fourteen-three-three peptide inhibitor), peptide inhibitors against 14-3-3 proteins, are available, however, specific inhibitors against each 14-3-3 isoforms have not been developed for the therapeutic purpose [57]. Instead, a gene therapy using shRNA against $14-3-3 \gamma$ in a cell typespecific manner could be one promising way to ameliorate

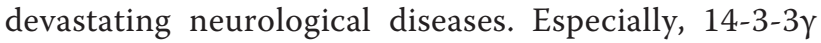
has been deeply involved in neurological diseases; inflammatory joint diseases [58], Alzheimer's diseases [59], Parkinson's disease [60], multiple sclerosis [31], and Creutzfeldt-Jakob disease [61,62]. Whereas TRPM4b channels have not been studied in these diseases, 14-3-3ymediated TRPM4b trafficking might be involved in the neuronal cell death in these diseases.

\section{Conclusions}

TRPM4b channels are $\mathrm{Ca}^{2+}$-activated, $\mathrm{Ca}^{2+}$-impermeable monovalent cation channels which are expressed in various neuronal tissues and involved in diverse physiological con-

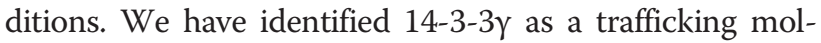
ecule for TRPM4b and Ser88 residue at the N-terminus of TRPM4b is critical for 14-3-3 $\gamma$ binding. Heterologous overexpression of 14-3-3 $\gamma$ showed the increased TRPM4b expression on the plasma membrane, in contrast, the surface expression of TRPM4b was greatly reduced by the knockdown of endogenous 14-3-3y. Glutamate-induced TRPM4b currents and glutamate-induced neurotoxicity in HT-22 cells were attenuated by a TRPM4b specific antag-

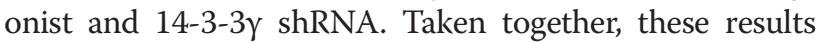
suggested that specific inhibition of $14-3-3 \gamma$-mediated trafficking of TRPM4b channels provide a new therapeutic target against neuronal cell death.

\section{Methods}

\section{Chemicals}

Ionomycin, 9-phenanthrol, 3-(4,5-dimethyl-2-thiazolyl)2,5-diphenyl-2H-tetrazolium bromide (MTT) and all other chemicals were purchased from Sigma Aldrich.

\section{Plasmid and shRNA construction}

The cDNA encoding for full-length human TRPM4b (Genebank accession no. NM_017636), mouse TRPM4b

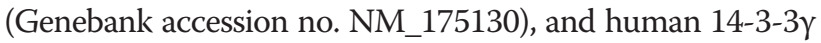
(Genebank accession no. NM_012479) were obtained by the PCR-based gateway cloning method (Invitrogen). The cDNAs of 14-3-3 isoforms were kindly provided by Dr. Dukryong Kim (Gyeoungsang National University). TRPM4b-N174 was generated from the full-length cDNA, and its phosphorylation mutants (T19A, T42A and S88A) were made by EZchange site directed mutagenesis kit (Enzynomics). All constructs were cloned into several vectors, including pDEST-EGFP-C, pDEST-mCherry-C, pDEST-FLAG-C, pDEST-HA-C by gateway cloning. The

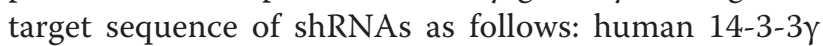

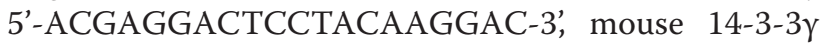
5'-GGACAACTACCTGATCAAGAA-3, mouse TRPM4b 5'-GCTGGATCCCTAAGATCTTCA-3'.

\section{Yeast two-hybrid screening}

The N-termini of human TRPM4b (N174) was ligated into pGBKT7 encoding for the GAL4 DNA binding domain (BD) and human cDNA library was cloned into pGADT7 encoding for the activation domain (AD). BD/TRPM4b-N174 and AD/cDNA library were cotransformed into the yeast strain AH109 in order to find protein-protein interactions with TRPM4b-N174. AH109 was unable to synthesize histidine but AD/14-3-3y was found to grow on His minimal medium by permitting histidine biosynthesis.

\section{Cell culture and transfection}

HEK293T and HT-22 cells were purchased from the Korean Cell Line Bank (Seoul National University) and cultured in DMEM (Invitrogen) supplemented with $10 \%$ fetal bovine serum (Invitrogen), 100 units per $\mathrm{ml}$ penicillin-streptomycin (Invitrogen) at $37^{\circ} \mathrm{C}$ in a humidified atmosphere of $95 \% \mathrm{O}_{2}$ and $5 \% \mathrm{CO}_{2}$. Transfection of 
expression vectors was performed with Lipofectamine 2000 (Invitrogen) according to the manufacturer's protocol.

\section{Co-immunoprecipitation and immunoblotting}

For co-immunoprecipitation, whole-cell lysates were mixed at $4^{\circ} \mathrm{C}$ with $1 \mu \mathrm{g} / \mathrm{ml}$ anti-FLAG (M2, sigma) antibodies in lysis buffer (in $\mathrm{mM}, 50$ Tris- $\mathrm{HCl}$ (pH 7.4), $150 \mathrm{NaCl}, 5$ EDTA, 1 PMSF and 1\% NP-40) containing a proteaseinhibitor cocktail (Roche). Immune complexes were incubated by binding to mixed protein A/G PLUS-Agarose (Santa Cruz Biotechnology) for $1 \mathrm{hr}$, and washed four times with lysis buffer. For immunoblotting, Proteins were separated by $10 \%$ SDS-PAGE gel and blotted onto PVDF membranes. The blots were blocked with 5\% skim-milk in TBST at room temperature for $20 \mathrm{~min}$ and incubated for overnight at $4^{\circ} \mathrm{C}$ with anti-GFP antibody (1:500, Santa Cruz Biotechnology), anti-FLAG (1:1000, Sigma) or anti-HA antibody (1:500, Roche). Blots were then washed and incubated with horse-radish peroxidase conjugated goat anti-mouse IgG, followed by washing and detection of immunoreactivity with the enhanced chemiluminescence (Amersham Biosciences).

\section{GST pull-down experiment}

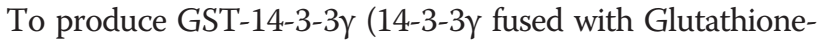
S-transferase) construct, the full-length human 14-3-3y was cloned into the pDEST15 vector (Invitrogen) via the gate-

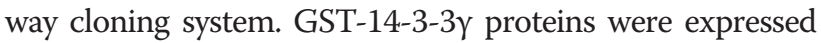
in bacteria and purified according to the manufacturer's protocol (Amersham Biosciences). Cell lysates obtained from wildtype or mutants of TRPM4b-N174 transfected

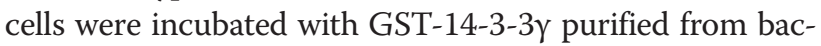
teria for $2 \mathrm{hrs}$, and then incubated with glutathioneSepharose 4B beads (Amersham Biosciences). After 2 hrs incubation at $4^{\circ} \mathrm{C}$, the beads were washed four times with ice cold lysis buffer. Bound proteins were eluted with SDS sample buffer, separated on 10\% SDS-PAGE gels, and analyzed by Western blot.

\section{Cell Surface biotinylation}

For surface biotinylation, the cell membrane proteins of GFP-TRPM4b transfected HEK293T cells were biotinylated with PBS containing Sulfo-NHS-SS-biotin (Pierce) at $4^{\circ} \mathrm{C}$ for $30 \mathrm{~min}$. After biotinylation, cells were washed with quenching buffer (100 mM glycine in PBS) to remove excess biotin and washed three times with PBS. The cells were then lysed and incubated with high capacity NeutrAvidin-Agarose Resin (Thermo Science). After three washes with lysis buffer, bound proteins are eluted by SDS sample buffer and subjected to Western blot analysis.

Bimolecular fluorescence complementation (BIFC) experiment TRPM4b and 14-3-3 $\gamma$ were cloned into bimolecular fluorescence complement (pBiFC)-VN173 and pBIFC-VC173 vectors. HEK293T cells were co-transfected with cloned $\mathrm{BiFC}$ vectors and transfected with DsRed-Mem for the detection of plasma membrane. These cells were fixed with 4\% paraformaldehyde for $20 \mathrm{~min}$ at room temperature and mounted with Dako fluorescence mounting medium. Venus fluorescence signals were observed by confocal microscopy (Nikon A1).

\section{Image analysis}

Cell surface expression of TRPM4b was determined using a confocal microscope. HEK293T cells were plated onto glass coverslips and co-transfected with GFP-TRPM4b and DsRed-Mem. The cells were cultured for additional 24 hrs, washed twice with PBS, and directly observed under a confocal microscope. Pearson's correlation coefficients were calculated from the co-localization signals at the edge region of cells using the Nikon A1 confocal software.

\section{Electrophysiology}

The standard solution for bath and pipette contained, in $\mathrm{mM}: 1 \mathrm{MgCl}_{2}, 5.5$ glucose, and 10 HEPES. Na-gluconate (bath, 145 and pipette, 120) was used. Pipette solution contained $10 \mathrm{mM}$ EGTA and $\mathrm{pH}$ was adjusted with $\mathrm{NaOH}$ to 7.2 , while bath solution contained $2 \mathrm{mM} \mathrm{CaCl}_{2}$ and adjusted to $\mathrm{pH}$ 7.35. $\mathrm{K}^{+}$was not included in either recording or pipette solution to eliminate the $\mathrm{Ca}^{2+}$-activated $\mathrm{K}^{+}$channels which might be endogenously expressed in either HT293T or HT-22 cells. In a few initial experiments, tetraethylammonium (TEA, $2 \mathrm{mM}$ ) was added to the bath solution, however, it did not show any difference from the data with no TEA. Therefore, the data with and without TEA were pooled. Patch pipettes were made from borosilicate glass capillaries (Warner Instruments, Inc.). Whole-cell currents were recorded using a patch clamp amplifier (Axopatch 200B, Axon Instrument, Inc.). The current-voltage relations were measured by applying ramp pulses (from $-100 \mathrm{mV}$ to $+100 \mathrm{mV}$ during $400 \mathrm{~ms}$ ) from a holding potential of $0 \mathrm{mV}$ at room temperature. The sampling interval was $200 \mu$ s and the filter setting was $2 \mathrm{KHz}$. Currents were analyzed with Clampfit software (Axon instruments, Inc.). Ionomycin $(1 \mu \mathrm{M})$ was used to activate TRPM4b channels overexpressed in HEK293T cells. The current densities were calculated by subtracting the amplitude of initial currents from activated TRPM4b currents and divided by cell capacitance. A TRPM4b inhibitor, 9-phenanthrol $(100 \mu \mathrm{M})$ was applied when glutamateinduced TRPM4b currents reached to near maximum values (usually $10-20$ minutes after glutamate $(1 \mathrm{mM})$ application) to measure the inhibition in HT-22 cells.

\section{Real-time quantitative RT-PCR (qRT-PCR)}

Total RNA was isolated from HT-22 cells and primary cultured hippocampal neurons using a RNA purification 
kit (GeneAll) according to the manufacturer's instruction. The cDNA was synthesized from $1 \mu \mathrm{g}$ of total RNA and reverse transcription was performed with SuperScript ${ }^{\circ}$ VILO $^{\mathrm{ma}}$ cDNA Synthesis Kit (Invitrogen). The qRT-PCR was done with a SensiFAST ${ }^{\text {tu }}$ Probe Hi-ROX Kit (Bioline) using the TaqMan probe Mm.PT.58.8488376 (IDT). GAPDH was used as an endogenous control. The $2^{-\Delta \Delta C t}$ method was used to calculate fold changes in gene expression [63].

\section{MTT cell viability experiment}

Cell viability of HT-22 cells was assessed by MTT assay [64]. 9-phenanthrol $(1,3$ and $10 \mu \mathrm{M})$ was applied $30 \mathrm{~min}$ before incubating in glutamate $(5 \mathrm{mM})$ for $18 \mathrm{hr}$. After treatment, MTT reagent (5 $\mathrm{mg} / \mathrm{ml}$ in PBS) was added to the culture wells, incubated for $3 \mathrm{hr}$, and the samples were lysed with Dimethyl Sulfoxide (DMSO). MTT is reductively converted into a violet formazan derivative, which is quantified photometrically at $570 \mathrm{~nm}$ in a well plate reading system (Infinite M200 pro). The mean values from the readings of triplicate wells were taken as one value. The optical density value for the control cultures was considered as $100 \%$ viability (control) and viability in other samples is expressed as a percentage of viability in the control culture.

\section{Statistical analysis}

Numerical data are presented as means \pm SEM. Error bars in graphs denote the standard error of the mean. The statistical significance of data was assessed by unpaired or paired Student's $t$-test. The significance level is displayed as asterisks (" $\mathrm{P}<0.05$ or ${ }^{* * *} \mathrm{P}<0.01$, $\left.{ }^{\text {****** }} \mathrm{p}<0.001\right)$.

\section{Additional files}

Additional file 1: Figure S1. (A) Inverse Co-IP experiment. GFP-TRPM4b (4b) or GFP-TRPM4b-N174 (N174) was transfected with or without FLAG-14-3-3y in HEK293T cells and cell lysates were then immunoprecipitated using anti-GFP antibody. Immunoprecipitates were examined by Western blotting using anti-FLAG antibody (upper panel). Input represented 5\% of cell lysates used in the Co-IP experiment (lower panel). (B) BiFC experiment with VC-TRPM4a with and without VN-14-3-3y (top panel) and VN-14-3-30 with and without VC-TRPM4b were shown (bottom panel). Weak Venus signals were detected by the yellow color (arrow) compared to the Figure 1D. Scale bar, $10 \mu \mathrm{m}$.

Additional file 2: Figure S2. (A) The current densities were obtained from whole-cell currents of non-transfected HEK293T cells (black; $n=7$ ), cells transfected with GFP-TRPM4b (green; $n=7$ ), and cells co-transfected with GFP-TRPM4b and 14-3-3y (red; $n=9$ ). Currents were activated by $30 \mu M$ $\left[\mathrm{Ca}^{2+}\right]_{i}$ and the voltage-ramp $(-100 \mathrm{mV}$ to $+100 \mathrm{mV}$. These overexpressed TRPM4b currents showed linear I-V relationships as previously shown when high $\left[\mathrm{Ca}^{2+}\right]_{i}$ was used [15]. (B) Summary bar graph of TRPM4b currents with or without 14-3-3y co-expression was plotted at $-100 \mathrm{mV}$ and $+100 \mathrm{mV}$ $\left({ }^{* * *} \mathrm{p}<0.001\right)$. All values are mean $\pm \mathrm{SEM}$.

Additional file 3: Figure S3. (A) Activation time-course of TRPM4b-mediated currents elicited by glutamate $(1 \mathrm{mM})$ application in HT-22 cells $(n=6)$. (B) A representative trace of whole cell recording showed that pre-incubation (5-15 min) of 9-phenanthrol $(100 \mu \mathrm{M})$ failed to activate endogenous TRPM4b-mediated currents elicited by 10 min application of glutamate $(1 \mathrm{mM})$ in HT-22 cells $(n=4 ; 0.292 \pm 0.139 \mathrm{pA} / \mathrm{pF}$ increased at $+100 \mathrm{mV}$ ). Note that raw traces were activated by voltage ramp $(-100$ to $+100 \mathrm{mV}$ ) before (black) and $10 \mathrm{~min}$ after (red) glutamate application were overlapped. (C) Summary bar graph of qRT-PCR of TRPM4b in HT-22 cells. The level of endogenous TRPM4b mRNA in HT-22 cells was comparable to the one in mouse primary cultured hippocampal neurons. (D) Validation of mouse TRPM4b shRNA constructs. HEK293T cells were co-transfected with GFP-TRPM4b and TRPM4b shRNA] or shRNA2 and their knockdown efficiency was evaluated by Western blot using anti-GFP antibody against GFP-TRPM4b.

\section{Abbreviations}

CHPG: [(RS)-chloro-5-hydroxyphenylglycine]; GFP: (Green Fluorescent Protein); MPEP: (2-methyl-6-(phenylethynyl)-pyridine).

\section{Competing interests}

Authors declare no conflict of interests.

\section{Authors' contribution}

Drs. C-HC and EK have planned and performed the experiment and discussed the results with Drs. EMH, S-GH and J-YP and written the manuscript together. Dr. OY and Y-SL contributed to the study by performing some experiments (electrophysiology and biotinylation respectively). All authors read and approved the final manuscript.

\section{Acknowledgement}

This work was supported by the National Research Foundation funded by the Korean Ministry of Science, Education and Technology (WCI 2009-003 and 2009-0067148).

\section{Author details}

${ }^{1} \mathrm{WCI}$ Center for functional connectomics, Korea Institute of Science and Technology (KIST), Seoul 136-791, Republic of Korea. ${ }^{2}$ College of Life Sciences and Biotechnology, Korea University, Anam-ro 145, Seongbuk-gu, Seoul, Republic of Korea. ${ }^{3}$ Department of Physiology, Institute of Health Science and Medical Research Center for Neural Dysfunction, Gyeongsang National University School of Medicine, Jinju 660-51, Republic of Korea. ${ }^{4}$ Neuroscience program, University of Science and Technology (UST), Daejeon 305-350, Republic of Korea.

Received: 7 April 2014 Accepted: 14 July 2014

Published: 22 July 2014

\section{References}

1. Ross WN: Changes in intracellular calcium during neuron activity. Annu Rev Physiol 1989, 51:491-506.

2. Marks AR: Intracellular calcium-release channels: regulators of cell life and death. Am J Physiol 1997, 272(2 Pt 2):H597-H605.

3. Burnashev N: Calcium permeability of ligand-gated channels. Cell Calcium 1998, 24(5-6):325-332.

4. Ramsey IS, Delling M, Clapham DE: An introduction to TRP channels. Annu Rev Physiol 2006, 68:619-647.

5. Catterall WA: Voltage-gated calcium channels. Cold Spring Harb Perspect Biol 2011, 3(8):a003947.

6. Hartzell C, Putzier I, Arreola J: Calcium-activated chloride channels. Annu Rev Physiol 2005, 67:719-758.

7. Huang $F$, Wong $X$, Jan $L Y$ : International union of basic and clinical pharmacology. LXXXV: calcium-activated chloride channels. Pharmacol $\operatorname{Rev} 2012,64(1): 1-15$

8. Sommer B, Seeburg PH: Glutamate receptor channels: novel properties and new clones. Trends Pharmacol Sci 1992, 13(7):291-296.

9. Jonas P: AMPA-type glutamate receptors-nonselective cation channels mediating fast excitatory transmission in the CNS. EXS 1993, 66:61-76.

10. Strübing C, Krapivinsky G, Krapivinsky L, Clapham DE: TRPC1 and TRPC5 form a novel cation channel in mammalian brain. Neuron 2001, 29(3):645-655

11. Liu SJ, Savtchouk I: $\mathrm{Ca}^{2+}$ permeable AMPA receptors switch allegiances: mechanisms and consequences. J Physiol 2012, 590(Pt 1):13-20. 
12. Colquhoun $D$, Neher $E$, Reuter $H$, Stevens CF: Inward current channels activated by intracellular Ca in cultured cardiac cells. Nature 1981, 294(5843):752-754

13. Maruyama $Y$, Petersen $\mathrm{OH}$ : Cholecystokinin activation of single-channel currents is mediated by internal messenger in pancreatic acinar cells. Nature 1982, 300(5887):61-63.

14. Hofmann T, Chubanov V, Gudermann T, Montell C: TRPM5 is a voltage-modulated and $\mathrm{Ca}^{2+}$-activated monovalent selective cation channel. Curr Biol 2003, 13(13):1153-1158.

15. Launay $\mathrm{P}$, Cheng $\mathrm{H}$, Srivatsan S, Penner R, Fleig A, Kinet JP: TRPM4 regulates calcium oscillations after $\mathrm{T}$ cell activation. Science 2004, 306(5700):1374-1377.

16. Launay P, Fleig A, Perraud AL, Scharenberg AM, Penner R, Kinet JP: TRPM4 is a $\mathrm{Ca}^{2+}$-activated nonselective cation channel mediating cell membrane depolarization. Cell 2002, 109(3):397-407.

17. Guinamard R, Demion M, Launay P: Physiological roles of the TRPM4 channel extracted from background currents. Physiology (Bethesda) 2010, 25(3):155-164

18. Fleig A, Penner R: The TRPM ion channel subfamily: molecular, biophysical and functional features. Trends Pharmacol Sci 2004, 25(12):633-639.

19. Venkatachalam K, Montell C: TRP channels. Annu Rev Biochem 2007 76:387-417

20. Xu XZ, Moebius F, Gill DL, Montell C: Regulation of melastatin, a TRP-related protein, through interaction with a cytoplasmic isoform. Proc Natl Acad Sci US A 2001, 98(19):10692-10697.

21. Fonfria E, Murdock PR, Cusdin FS, Benham CD, Kelsell RE, McNulty S: Tissue distribution profiles of the human TRPM cation channel family. J Recept Signal Transduct Res 2006, 26(3):159-178.

22. Yoo JC, Yarishkin OV, Hwang EM, Kim E, Kim DG, Park N, Hong SG, Park JY: Cloning and characterization of rat transient receptor potentialmelastatin 4 (TRPM4). Biochem Biophys Res Commun 2010, 391(1):806-811.

23. Kruse M, Schulze-Bahr E, Corfield V, Beckmann A, Stallmeyer B, Kurtbay G, Ohmert I, Schulze-Bahr E, Brink P, Pongs O: Impaired endocytosis of the ion channel TRPM4 is associated with human progressive familial heart block type I. J Clin Invest 2009, 119(9):2737-2744.

24. Liu H, El Zein L, Kruse M, Guinamard R, Beckmann A, Bozio A, Kurtbay G, Mégarbané A, Ohmert I, Blaysat G, Villain E, Pongs O, Bouvagnet $P$ : Gain-of-function mutations in TRPM4 cause autosomal dominant isolated cardiac conduction disease. Circ Cardiovasc Genet 2010, 3(4):374-385.

25. Stallmeyer B, Zumhagen S, Denjoy I, Duthoit G, Hébert JL, Ferrer $X$, Maugenre S, Schmitz W, Kirchhefer U, Schulze-Bahr E, Guicheney P, SchulzeBahr E: Mutational spectrum in the $\mathrm{Ca}^{2+}$-activated cation channel gene TRPM4 in patients with cardiac conductance disturbances. Hum Mutat 2012, 33(1):109-117.

26. Gerzanich V, Woo SK, Vennekens R, Tsymbalyuk O, Ivanova S, Ivanov A Geng Z, Chen Z, Nilius B, Flockerzi V, Freichel M, Simard JM: De novo expression of Trpm4 initiates secondary hemorrhage in spinal cord injury. Nat Med 2009, 15(2):185-191.

27. Loh KP, Ng G, Yu CY, Fhu CK, Yu D, Vennekens R, Nilius B, Soong TW, Liao P: TRPM4 inhibition promotes angiogenesis after ischemic stroke. Pflugers Arch 2014, 466(3):563-576.

28. Mironov SL, Skorova EY: Stimulation of bursting in pre-Bötzinger neurons by Epac through calcium release and modulation of TRPM4 and K-ATP channels. J Neurochem 2011, 117(2):295-308.

29. Teruyama R, Sakuraba M, Kurotaki H, Armstrong WE: Transient receptor potential channel $\mathrm{m} 4$ and $\mathrm{m} 5$ in magnocellular cells in rat supraoptic and paraventricular nuclei. J Neuroendocrinol 2011, 23(12):1204-1213.

30. Mrejeru A, Wei A, Ramirez JM: Calcium-activated non-selective cation currents are involved in generation of tonic and bursting activity in dopamine neurons of the substantia nigra pars compacta. J Physiol 2011, 15:589(Pt 10):2497-2514

31. Schattling B, Steinbach $K$, Thies E, Kruse M, Menigoz A, Ufer F, Flockerzi V, Brück W, Pongs O, Vennekens R, Kneussel M, Freichel M, Merkler D, Friese MA: TRPM4 cation channel mediates axonal and neuronal degeneration in experimental autoimmune encephalomyelitis and multiple sclerosis. Nat Med 2012, 18(12):1805-1811.

32. Kim YS, Kang E, Makino Y, Park S, Shin JH, Song H, Launay P, Linden DJ: Characterizing the conductance underlying depolarization-induced slow current in cerebellar Purkinje cells. J Neurophysio/ 2013, 109(4):1174-1181
33. Hu CD, Chinenov $Y$, Kerppola TK: Visualization of interactions among bZIP and Rel family proteins in living cells using bimolecular fluorescence complementation. Mol Cell 2002, 9(4):789-798

34. Mackintosh C: Dynamic interactions between 14-3-3 proteins and phosphoproteins regulate diverse cellular processes. Biochem J 2004, 381:329-342.

35. Davis JB, Maher P: Protein kinase $C$ activation inhibits glutamate-induced cytotoxicity in a neuronal cell line. Brain Res 1994, 652(1):169-173.

36. Grand T, Demion M, Norez C, Mettey Y, Launay P, Becq F, Bois P, Guinamard R: 9-phenanthrol inhibits human TRPM4 but not TRPM5 cationic channels. Br J Pharmacol 2008, 153(8):1697-1705.

37. Amarouch MY, Syam N, Abriel H: Biochemical, single-channel, whole-cell patch clamp, and pharmacological analyses of endogenous TRPM4 channels in HEK293 cells. Neurosci Lett 2013, 541:105-110.

38. Qiao H, Foote M, Graham K, Wu Y, Zhou Y: 14-3-3 proteins are required for hippocampal long-term potentiation and associative learning and memory. J Neurosci 2014, 34(14):4801-4808.

39. Berg D, Holzmann C, Riess O: 14-3-3 proteins in the nervous system. Nat Rev Neurosci 2003, 4(9):752-762.

40. Umahara T, Uchihara T, Nakamura A, Iwamoto T: Differential expression of 14-3-3 protein isoforms in developing rat hippocampus, cortex, rostral migratory stream, olfactory bulb, and white matter. Brain Res 2011, 1410:1-11.

41. Foote M, Zhou Y: 14-3-3 proteins in neurological disorders. Int J Biochem Mol Biol 2012, 3(2):152-164

42. Couve A, Kittler JT, Uren JM, Calver AR, Pangalos MN, Walsh FS, Moss SJ: Association of GABA(B) receptors and members of the 14-3-3 family of signaling proteins. Mol Cell Neurosci 2001, 17(2):317-328.

43. Kagan A, Melman YF, Krumerman A, McDonald TV: 14-3-3 amplifies and prolongs adrenergic stimulation of HERG $\mathrm{K}+$ channel activity. EMBO $J$ 2002, 21(8):1889-1898.

44. O'Kelly I, Butler MH, Zilberberg N, Goldstein SA: Forward transport. 14-3-3 binding overcomes retention in endoplasmic reticulum by dibasic signals. Cell 2002, 111(4):577-588.

45. Rajan S, Preisig-Müller R, Wischmeyer E, Nehring R, Hanley PJ, Renigunta V, Musset B, Schlichthörl G, Derst C, Karschin A, Daut J: Interaction with 14-33 proteins promotes functional expression of the potassium channels TASK-1 and TASK-3. J Physiol 2002, 545(Pt 1):13-26.

46. Allouis M, Le Bouffant F, Wilders R, Péroz D, Schott JJ, Noireaud J, Le Marec H, Mérot J, Escande D, Baró I: 14-3-3 is a regulator of the cardiac voltage-gated sodium channel Nav1.5. Circ Res 2006, 98(12):1538-1546.

47. Exley R, Moroni M, Sasdelli F, Houlihan LM, Lukas RJ, Sher E, Zwart R, Bermudez I: Chaperone protein 14-3-3 and protein kinase $A$ increase the relative abundance of low agonist sensitivity human a $4 \beta 2$ nicotinic acetylcholine receptors in Xenopus oocytes. J Neurochem 2006, 98(3):876-885.

48. Heusser K, Yuan H, Neagoe I, Tarasov Al, Ashcroft FM, Schwappach B: Scavenging of 14-3-3 proteins reveals their involvement in the cell-surface transport of ATP-sensitive K+ channels. J Cell Sci 2006, 119(Pt 20):4353-4363.

49. Li Y, Wu Y, Zhou Y: Modulation of inactivation properties of CaV2.2 channels by 14-3-3 proteins. Neuron 2006, 51(6):755-771.

50. Vivithanaporn P, Yan S, Swanson GT: Intracellular trafficking of KA2 kainate receptors mediated by interactions with coatomer protein complex I (COPI) and 14-3-3 chaperone systems. J Biol Chem 2006, 281(22):15475-15484.

51. Czirják G, Vuity D, Enyedi P: Phosphorylation-dependent binding of 14-3-3 proteins controls TRESK regulation. J Biol Chem 2008, 283(23):15672-15680.

52. Chen BS, Roche KW: Growth factor-dependent trafficking of cerebellar NMDA receptors via protein kinase B/Akt phosphorylation of NR2C. Neuron 2009, 62(4):471-478

53. Sun C, Qiao H, Zhou Q, Wang Y, Wu Y, Zhou Y, Li Y: Modulation of GluK2a subunit-containing kainate receptors by 14-3-3 proteins. J Biol Chem 2013, 288(34):24676-24690.

54. Sokolowski B, Orchard S, Harvey M, Sridhar S, Sakai Y: Conserved BK channel-protein interactions reveal signals relevant to cell death and survival. PLoS One 2011, 6(12):e28532.

55. Crnich R, Amberg GC, Leo MD, Gonzales AL, Tamkun MM, Jaggar JH, Earley S: Vasoconstriction resulting from dynamic membrane trafficking of TRPM4 in vascular smooth muscle cells. Am J Physiol Cell Physiol 2010, 299(3):C682-C694.

56. Nilius B, Prenen J, Tang J, Wang C, Owsianik G, Janssens A, Voets T, Zhu MX: Regulation of the $\mathrm{Ca}^{2+}$ sensitivity of the nonselective cation channel TRPM4. J Biol Chem 2005, 280(8):6423-6433. 
57. Masters SC, Fu H: 14-3-3 proteins mediate an essential anti-apoptotic signal. J Biol Chem 2001, 276(48):45193-45200.

58. Kilani RT, Maksymowych WP, Aitken A, Boire G, St-Pierre Y, Li Y, Ghahary A: Detection of high levels of 2 specific isoforms of 14-3-3 proteins in synovial fluid from patients with joint inflammation. J Rheumatol 2007, 34(8):1650-1657.

59. Fountoulakis M, Cairns N, Lubec G: Increased levels of 14-3-3 gamma and epsilon proteins in brain of patients with Alzheimer's disease and Down syndrome. J Neural Transm Suppl 1999, 57:323-335.

60. Yacoubian TA, Slone SR, Harrington AJ, Hamamichi S, Schieltz JM, Caldwell KA, Caldwell GA, Standaert DG: Differential neuroprotective effects of 14-3-3 proteins in models of Parkinson's disease. Cell Death Dis 2010, 1:e2.

61. Takahashi H, Iwata T, Kitagawa Y, Takahashi RH, Sato Y, Wakabayashi H, Takashima M, Kido H, Nagashima K, Kenney K, Gibbs CJ Jr, Kurata T: Increased levels of epsilon and gamma isoforms of 14-3-3 proteins in cerebrospinal fluid in patients with Creutzfeldt-Jakob disease. Clin Diagn Lab Immunol 1999, 6(6):983-985.

62. Takahashi S, Shibata M, Fukuuchi Y: Role of sodium ion influx in depolarization-induced neuronal cell death by high $\mathrm{KCl}$ or veratridine. Eur J Pharmacol 1999, 372(3):297-304

63. Livak KJ, Schmittgen TD: Analysis of relative gene expression data using real-time quantitative PCR and the 2(-Delta Delta C(T)) Method. Methods 2001, 25:402-408.

64. van Meerloo J, Kaspers GJ, Cloos J: Cell sensitivity assays: the MTT assay. Methods Mol Biol 2011, 731:237-245.

doi:10.1186/s13041-014-0052-3

Cite this article as: Cho et al:: Depletion of $14-3-3 \gamma$ reduces the surface expression of Transient Receptor Potential Melastatin 4b (TRPM4b) Channels and attenuates TRPM4b-mediated glutamate-induced neuronal cell death. Molecular Brain 2014 7:52

\section{Submit your next manuscript to BioMed Central and take full advantage of:}

- Convenient online submission

- Thorough peer review

- No space constraints or color figure charges

- Immediate publication on acceptance

- Inclusion in PubMed, CAS, Scopus and Google Scholar

- Research which is freely available for redistribution 